\title{
Dirofilariose pulmonar humana: relato de sete casos $^{*}$
}

\begin{abstract}
Rodrigo Silva CavallazzI ${ }^{1}$, Antônio César CavallazzI², Irene Vieira Souza², João José de Deus Cardoso²
Dirofilariose pulmonar humana é uma doença rara causada pelo parasita Dirofilaria immitis.

Apresenta-se usualmente como um nódulo pulmonar solitário que mimetiza câncer de pulmão.

Embora considerada uma doença clinicamente benigna, uma biópsia pulmonar excisional é quase

sempre necessária para o diagnóstico. Relatam-se as características epidemiológicas, clínicas e

radiológicas de sete casos de dirofilariose pulmonar humana em Florianópolis. De sete pacientes

relatados, seis tiveram como achado radiológico um nódulo pulmonar e foram submetidos à biópsia

pulmonar excisional para o diagnóstico. Em um paciente, a imagem radiológica não estava disponível

para revisão e, portanto, não foi descrita no trabalho; o diagnóstico foi estabelecido pela biópsia

transbrônquica. (J Pneumol 2002;28(2):100-102)
\end{abstract}

\section{Human pulmonary dirofilariasis: a report of seven cases}

Human pulmonary dirofilariasis is a rare disease caused by the parasite Dirofilaria immitis. It is usually seen as a solitary pulmonary nodule that mimics lung cancer. Although this disease is considered benign, its diagnosis often requires an excisional lung biopsy. Herein we report the epidemiological, clinical and radiological features observed in seven cases of human pulmonary dirofilariasis from Florianópolis. Six of our seven patients, showed a radiological finding of pulmonary nodule and underwent excisional lung biopsy for diagnosis. In one case, the radiological image was unavailable for review. Therefore, it was not described in this work, and the diagnosis was established through transbronchial biopsy.

Descritores - Dirofilariose. Dirofilaria immitis. Lesão numular pulmonar. Neoplasias pulmonares.

Key words - Dirofilariasis. Dirofilaria immitis. Coin lesion pulmonary. Lung neoplasms.
Siglas e abreviaturas utilizadas neste trabalho

LILACS - Literatura Latino-Americana e do Caribe em Ciências da Saúde

ELISA - Enzime-linked imunosorbent assay

\section{INTRODUÇÃO}

Dirofilariose pulmonar humana é uma doença zoonótica, cuja apresentação mais comum é um nódulo pulmonar solitário que mimetiza câncer de pulmão. É causada pela forma larvária do parasita Dirofilaria immitis, um helminto da classe Nematoda. Em 1887, a descoberta do parasita no ventrículo esquerdo de uma criança do Rio de

\footnotetext{
* Trabalho realizado no Departamento de Clínica Médica da Universidade Federal de Santa Catarina.

1. Residente do 10 ano de Pneumologia da Unifesp.

2. Professor Adjunto.

Endereço para correspondência - Rodrigo Silva Cavallazzi, Rua Melo Alves, 530, apto. 83 - 01417-010 - São Paulo, SP. Tel./fax (11) 306201928; e-mail: rcavallazzi@bol.com.br

Recebido para publicação em 31/10/01. Aprovado, após revisão, em 1/2/02.
}

J aneiro foi relatada por Magalhães(1). Desde então, a forma pulmonar da doença vem sendo relatada em vários países, principalmente nos Estados Unidos.

\section{RELATO dOS CASOS}

Todos os pacientes eram da raça branca e residentes em Florianópolis.

Os pacientes 1 (sexo masculino, 73 anos) e 2 (sexo masculino, 42 anos) eram assintomáticos e tiveram um nódulo pulmonar descoberto incidentalmente na radiografia de tórax. No paciente 1 , a radiografia de tórax revelou um nódulo em lobo inferior direito, subpleural, não calcificado, de limites precisos, de configuração esférica e de $3,1 \mathrm{~cm}$ de diâmetro. No paciente 2 , 0 achado radiológico foi um nódulo em lobo inferior esquerdo, não calcificado, de limites precisos, de configuração esférica e de 


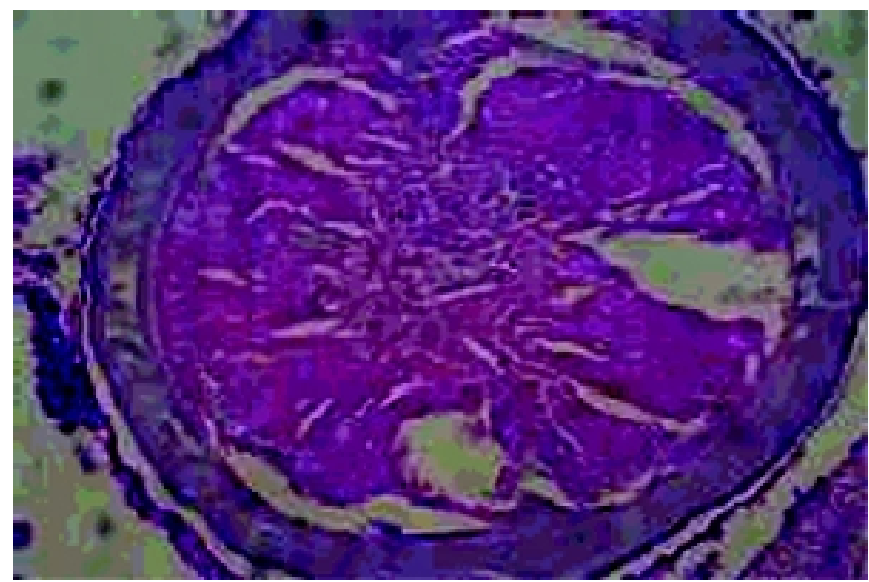

Figura 1 - Corte transversal do parasita. Hematoxilina-eosina: x250.

$2 \mathrm{~cm}$ de diâmetro. Ambos os pacientes tiveram como hipótese diagnóstica principal câncer de pulmão.

0 paciente 3 (sexo masculino, 70 anos) teve uma alteração descoberta na radiografia de tórax solicitada para seguimento de câncer de cólon que havia sido operado. Estava assintomático. 0 achado radiológico foi um nódulo no segmento basal anterior de lobo inferior direito, não calcificado, de limites imprecisos, de configuração esférica e de $4 \mathrm{~cm}$ de diâmetro. Suspeitou-se de metástase pulmonar.

0 paciente 4 (sexo masculino, 55 anos) apresentou dor torácica retroesternal inespecífica havia cinco anos. A radiografia de tórax revelou um nódulo em lobo superior direito, não calcificado, de limites precisos, de configuração esférica e de $3 \mathrm{~cm}$ de diâmetro. A hipótese diagnóstica principal foi de câncer de pulmão.

0 paciente 5 (sexo masculino, 44 anos) teve um quadro de rinorréia, tosse seca e febre baixa havia duas semanas. A radiografia de tórax mostrou um nódulo em lobo inferior direito, subpleural, não calcificado, de limites precisos, de configuração esférica e de $2 \mathrm{~cm}$ de diâmetro. A hipótese diagnóstica principal para o nódulo foi de câncer de pulmão.

0 paciente 6 (sexo feminino, 69 anos) apresentou tosse crônica e crepitações na ausculta respiratória. Suspeitou-se inicialmente de pneumonia e iniciou-se tratamento sem resposta. Estabeleceu-se o diagnóstico de dirofilariose pulmonar através do estudo histopatológico de amostra obtida por biópsia transbrônquica.

0 paciente 7 (sexo feminino, 63 anos) relatou dor em membro superior direito havia cinco meses. Não tinha queixas respiratórias. A radiografia de tórax revelou um nódulo em lobo superior direito, não calcificado, de limites precisos, de configuração esférica e de $0,5 \mathrm{~cm}$ de diâmetro. As principais hipóteses diagnósticas foram tuberculose e câncer de pulmão.

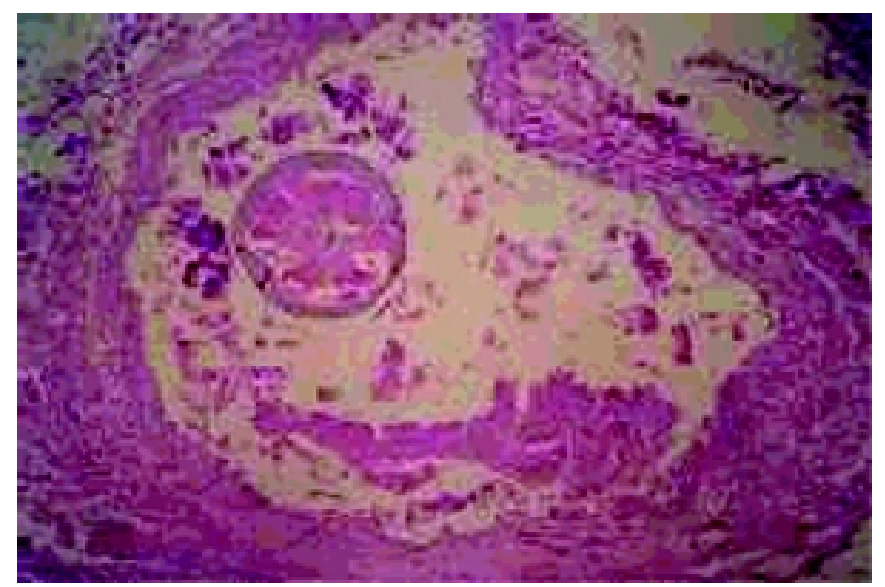

Figura 2 - Ramo da artéria pulmonar contendo o parasita. Hematoxilina-eosina: $x 100$.

Em nenhum caso havia eosinofilia. Com exceção da paciente que teve o diagnóstico estabelecido através do estudo da biópsia transbrônquica, todos os pacientes submeteram-se à biópsia pulmonar excisional. A análise histopatológica das amostras obtidas através das cirurgias determinou o diagnóstico de dirofilariose pulmonar nos pacientes.

$\mathrm{Na}$ macro e microscopia, os casos apresentaram aspectos superponíveis. $\mathrm{Na}$ macroscopia, foram observadas formações nodulares bem delimitadas, variando entre 1 e $2 \mathrm{~cm}$ de diâmetro, exibindo superfícies de corte branco-amareladas, com necrose central. Para microscopia, foram realizados cortes corados por hematoxilinaeosina, sendo observados nódulos bem delimitados, constituídos predominantemente de material necrótico, em meio do qual foram encontradas as estruturas parasitárias, com graus variáveis de necrose, por vezes sendo possível identificar que ocupavam a luz vascular. Na periferia do nódulo, observou-se anel fibroso, com quantidade variável de células inflamatórias predominantemente mononucleares, havendo de permeio eosinófilos, macrófagos e células gigantes multinucleadas tipo Langhans (Figuras 1 e 2).

\section{DISCUSSÃO}

Dirofilaria immitis é uma causa freqüente de doença cardíaca no cão, que é seu hospedeiro definitivo usual. 0 verme adulto reside no ventrículo direito do cão e forma uma massa parasitária. 0 hospedeiro intermediário e vetor é um mosquito (Culex, Aedes, Anopheles, entre outros gêneros) ${ }^{(2,3)}$. 0 homem é um hospedeiro inadequado para o desenvolvimento da larva da D. immitis. Acreditase que as larvas normalmente não sobrevivem no tecido subcutâneo do homem, mas ocasionalmente migram para o coração, onde se tornam um verme sexualmente ima- 
turo. Quando a morte do parasita ocorre, ele emboliza para o pulmão do homem, causando a doença dirofilariose pulmonar humana(4).

Os quatro principais fatores que influenciam a freqüência e distribuição da dirofilariose pulmonar humana são o tamanho da população canina, a prevalência de dirofilariose canina, a densidade da população de mosquito vetor e a exposição à picada de mosquitos vetores. A doença tem sido relatada principalmente nas regiões litorâneas. Nos casos relatados na literatura, há predominância no sexo masculino numa relação de 2:1 e no grupo de idade que varia de 40 a 59 anos $^{(5)}$. Em pesquisa na base de dados da LILACS, houve três casos de dirofilariose pulmonar humana relatados no Brasil(6-8). Milanez de Campos et al. ${ }^{(9)}$ realizaram um estudo retrospectivo de 24 casos da doença ocorridos em São Paulo no período de 1982 a 1996.

De 57 casos analisados por Ciferri, 41\% eram sintomáticos(5). Em outra análise de 24 casos de dirofilariose pulmonar, $46 \%$ eram sintomáticos e apresentavam-se com dor torácica, tosse, febre, hemoptise e dispnéia(9). Na radiografia de tórax, a lesão tipicamente aparece como um nódulo pulmonar solitário, esférico, não calcificado, circunscrito, de 1 a $4,5 \mathrm{~cm}$ de diâmetro ${ }^{(10)}$. A localização mais freqüente é subpleural ${ }^{(11)}$. Outras apresentações menos comuns incluem múltiplos nódulos pulmonares, infiltrado pulmonar e derrame pleural(9).

Os testes sorológicos para detecção de dirofilariose pulmonar humana possuem baixa especificidade. A descoberta recente da presença de anticorpo contra uma proteína específica da D. immitis (Di 22) pode aumentar

\section{REFERÊNCIAS}

1. Magalhães PS. Descripção de uma espécie de filárias encontradas no coração humano. Rev Cursos Prát Theor Fac Med Rio de J aneiro 1887; 3:129-215.

2. Robinson NB, Chavez CM, Conn JH. Pulmonary dirofilariasis in man. A case report and review of the literature. J Thorac Cardiovasc Surg 1977;74:403-8

3. Echeverri A, Long RF, Check W, Burnett CM. Pulmonary dirofilariasis. Ann Thorac Surg 1999;67:201-2.

4. Asimacopoulos PJ, Katras A, Christie B. Pulmonary dirofilariasis. The largest single-hospital experience. Chest 1992;102:851-5.

5. Ciferri F. Human pulmonary dirofilariasis in the United States: a critical review. Am J Trop Med Hyg 1982;31:302-8.

6. Schneider CAR, Mirra AP, J usto FA, Oyafuso M, Hidalgo GS, Chieffi $\mathrm{PP}$, et al. Dirofilariose pulmonar humana: relato de um caso e revisão da literatura. Acta Oncol Bras 1986;6:125-30.

7. Saad J $r$ R, Ethel Fo J, Próspero J D, Dorgan Neto V, Aguiar Neto J R. Dirofilariose pulmonar: relato de um caso. J Pneumol 1991;17:90-2

8. Amato VS, Amato Neto V, Uip DE, Boulos M. Novo caso de dirofilariose pulmonar humana adquirida no Brasil. Rev Soc Bras Med Trop $1995 ; 28: 285-6$ a especificidade do ELISA. No entanto, é necessária uma análise de um número maior de soros para validar esse teste ${ }^{(12)}$. A biópsia por aspiração com agulha fina tem baixa sensibilidade para o diagnóstico de dirofilariose pulmonar. 0 diagnóstico é usualmente feito pelo estudo histopatológico de amostra obtida através de toracotomia ou toracoscopia com biópsia pulmonar excisional. 0 não reconhecimento do parasita pode ocasionar um diagnóstico errado de infarto pulmonar ou granuloma necrosante ${ }^{(4)}$. O parasita é encontrado dentro de uma artéria pulmonar e freqüentemente ocupa uma posição excêntrica dentro do granuloma. Sua identificação é dada pelo achado de uma cutícula trilamelar, um feixe muscular somático espesso e um ou dois túbulos reprodutivos de localização central dentro da massa muscular. Entretanto, usualmente há degeneração do parasita e apenas fragmentos da cutícula são visíveis. Portanto, o diagnóstico definitivo depende de alto índice de suspeição(13).

A ressecção do nódulo não somente estabelece o diagnóstico como também a cura. Nos raros casos em que 0 parasita é identificado através da biópsia por aspiração com agulha fina, a cirurgia provavelmente não é desejável, uma vez que há evidência de que o nódulo pulmonar não cresce ${ }^{(4,14)}$. A ausência de calcificação do nódulo associada à idade avançada usual dos pacientes com dirofilariose pulmonar humana leva quase invariavelmente à hipótese de câncer de pulmão. Como a natureza do nódulo na maioria dos casos não é determinada de forma não invasiva, uma biópsia pulmonar é quase sempre realizada. Sendo uma doença benigna, a morbidez maior decorre da investigação diagnóstica.

9. Milanez de Campos JR, Barbas CS, Filomeno LT, Fernandez A, Minamoto $\mathrm{H}$, Filho $\mathrm{JV}$, et al. Human pulmonary dirofilariasis. Analysis of 24 cases from São Paulo, Brazil. Chest 1997;112:729-33.

10. Ro JY, Tsakalakis PJ, White VA, Luna MA, Chang-Tung EG, Green L, et al. Pulmonary dirofilariasis: the great imitator of primary or metastatic lung tumor. A clinicopathologic analysis of seven cases and a review of the literature. Hum Pathol 1989;20:69-76.

11. Flieder DB, Moran CA. Pulmonary dirofilariasis: a clinicopathologic study of 41 lesions in 39 patients. Hum Pathol 1999;30:251-6.

12. Perera L, Pérez-Arellano J L, Cordero M, Simón F, Muro A. Utility of antibodies against a $22 \mathrm{kD}$ molecule of Dirofilaria immitis in the diagnosis of human pulmonary dirofilariasis. Trop Med Int Health 1998;3: 151-5.

13. Merrill J R, Otis J, Logan WD, Davis MB. The dog heartworm (Dirofilaria immitis) in man. An epidemic pending or in progress? JAMA 1980;243:1066-8.

14. J elinek T, Schulte-Hillen J, Luscher T. Human dirofilariasis. Int J Dermatol 1996;35:872-5. 